\title{
A slow slip event in the Tokai area detected by tilt and seismic observation and its possible recurrence
}

\author{
Eiji Yamamoto, Shozo Matsumura, and Tadashi Ohkubo \\ National Research Institute for Earth Science and Disaster Prevention, 3-1 Tennodai, Tsukuba, Ibaraki 305-0006, Japan
}

(Received September 21, 2004; Revised August 5, 2005; Accepted August 6, 2005)

\begin{abstract}
In recent years, some anomalous crustal activities have been detected in the Tokai area, central Japan. First, a seismicity change was detected and was recognized to be the quiescence of microearthquake activities. Anomalous ground deformation was then detected in high-density GPS observations conducted by GSI, and also in tilt observations by NIED at the MKB station. East-southeast upward tilting of about 2 microradians from the middle of 2000 to the present is consistent with the result of the GPS observation. An analysis using the GPS data attributed the ground deformation to a slow slip occurring on the plate boundary beneath Lake Hamana, where distinct seismic quiescence has also been detected. Tilt observation at MKB began in 1981, so we have carefully examined past records to determine whether similar events have ever taken place. An anomalous tilt change of nearly the same direction as the current one and seismic quiescence evidently occurred simultaneously from 1988 to 1990. Apparently, a similar slow slip took place in almost the same place during this epoch. We speculate that slow-slip events beneath Lake Hamana have been repeatedly occurring under the steady subduction of the Philippine Sea plate. However, the magnitude and duration of the current slip now in progress are nearly twice those of the last slip (1988 to 1990). Therefore, a slow slip in this area may not repeat in exactly the same way. Though it is unclear how the ongoing event will proceed, redistribution of stress due to the slow slip may promote the anticipated Tokai earthquake. Careful monitoring and intense observation are necessary.
\end{abstract}

Key words: Slow slip, tilt observation, Tokai earthquake, earthquake prediction.

\section{Introduction}

In the Kanto and Tokai areas, located at the margin of the continental plate, large interplate earthquakes have occurred repeatedly due to subduction of the Philippine Sea plate. In the Tokai area in particular, the next earthquake is considered to be imminent because a seismic gap has continued since the 1854 Ansei Tokai earthquake (e.g. Ishibashi, 1981). The National Research Institute for Earth Science and Disaster Prevention (NIED) has conducted continuous microearthquake and tilt observations in both areas for the purpose of earthquake prediction since 1979. Also, the Geographical Survey Institute (GSI) has conducted highdensity GPS observation in both areas since the latter half of the 1990s. While data obtained through these observations have enhanced knowledge about plate coupling in the Tokai area, worrisome anomalies have recently been detected in the area.

Matsumura (1997) investigated the hypocenter distribution and focal mechanisms of microearthquakes and identified the locked zone of the plate interface, which is expected to become the source of the anticipated earthquake in the Tokai area. Furthermore, Matsumura (2002) found that the seismicity around this locked zone has decreased in the continental plate since 1997, and in the Philippine Sea slab since 1999 . This quiescence of seismicity may in-

Copyright (c) The Society of Geomagnetism and Earth, Planetary and Space Sciences (SGEPSS); The Seismological Society of Japan; The Volcanological Society of Japan; The Geodetic Society of Japan; The Japanese Society for Planetary Sciences; TERRAPUB dicate a decrease in stress corresponding to a partial slip of the plate boundary. If so, crustal movements due to plate boundary slip may be detected (Matsumura, 2001). The GPS observations conducted by GSI detected anomalous crustal movements that began in mid-2000 in the Tokai area. Ozawa et al. (2002) conducted an inversion analysis of these crustal movements and conjectured that these movements indicate the progress of a slow slip on the plate boundary beneath Lake Hamana. The NIED tilt observation at Mikkabi (MKB) also clearly detected a tilt change due to the slow slip event.

It is of great interest whether or not there have been other slow slip events in the same region. The MKB station has been operating since 1981 , so we are able to study the process over the past 20 years. We carefully investigated both the past tilt data taken at MKB and the quiescence of seismic activities. As a result of this study, we found that a phenomenon similar to the current slow slip occurred 15 years ago.

\section{Current Slow Slip Event}

NIED established tilt and seismic observation networks in the Kanto and Tokai areas under a special research project started in 1978. The first phase of the project was completed six years after the project's inception. Figure 1 depicts the locations of tilt observation points established by 1983 . The portion surrounded by broken lines in the figure represents the assumed focal zone of the Tokai earthquake (CDMC, 2001), the contours depict the uppermost 


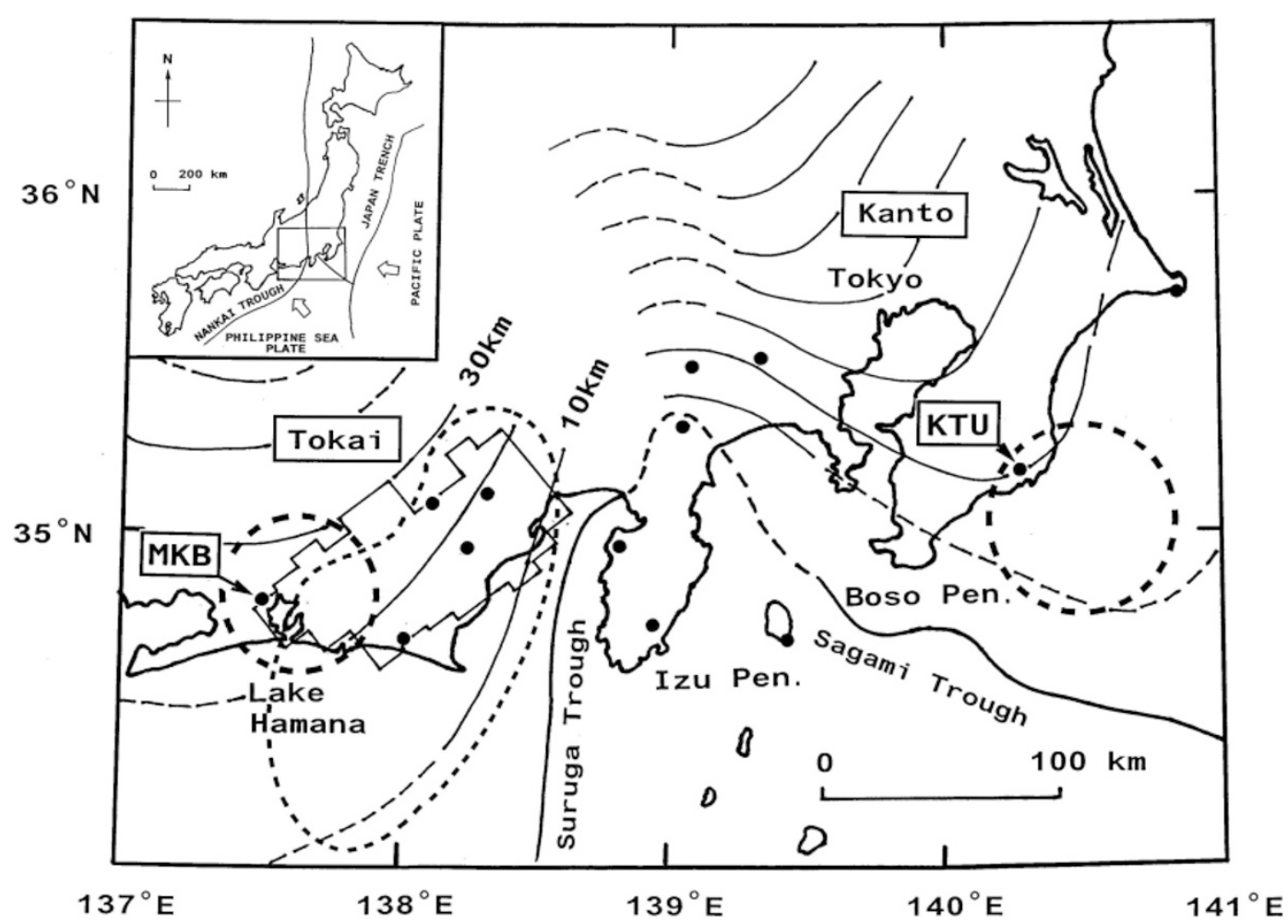

Fig. 1. Location of tilt observation stations installed at the bottom of 100 m-deep wells constructed by NIED as of 1983 . The eggplant-shaped zone surrounded by the dotted line is the assumed focal area of the anticipated Tokai earthquake (CDMC, 2001). The solid-line shape depicts the locked zone of the plate subduction inferred by Matsumura (1997). The contours show the uppermost isodepth of the Philippine Sea plate assumed by Ishida (1992). Slow slips have been detected both near Lake Hamana (Ozawa et al., 2002) and near the Boso peninsula (Ozawa et al., 2003; Sagiya, 2004), each of which is indicated by a thick dotted circle.

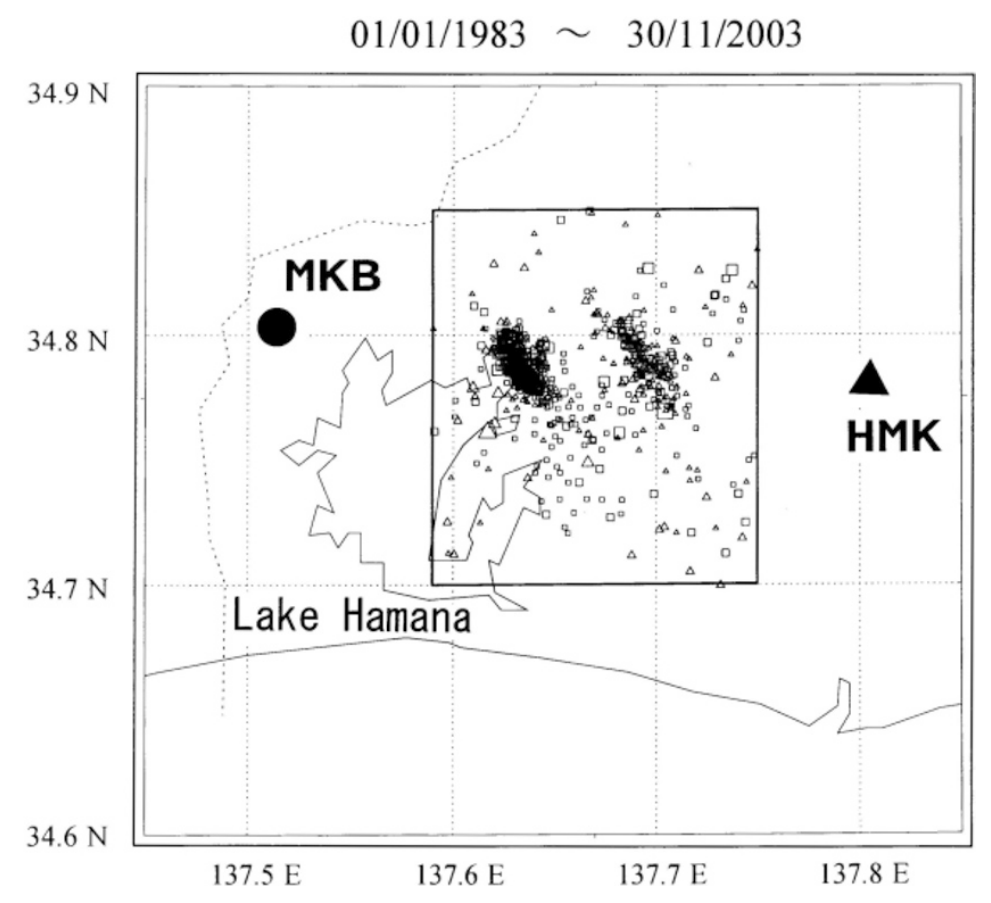

Fig. 2. Locations of the Mikkabi tilt station of NIED (MKB) and the Hamakita GPS station of GSI (HMK). Earthquakes treated in this paper were sampled within the rectangle located around the eastern part of Lake Hamana.

part of the Philippine Sea plate as assumed by Ishida (1992), and the portion surrounded by solid lines represents the inferred locked zone as proposed by Matsumura (1997). The two regions surrounded by thick broken circles located in the west (near Lake Hamana) and in the east (near the east coast of the Boso Peninsula) represent the areas of the slow slip that are judged to have occurred on the uppermost part of the Philippine Sea plate, as inferred from the inversion of anomalous crustal movements detected by GPS observation (Ozawa et al., 2002, 2003; Sagiya, 2004). Figure 2 depicts 


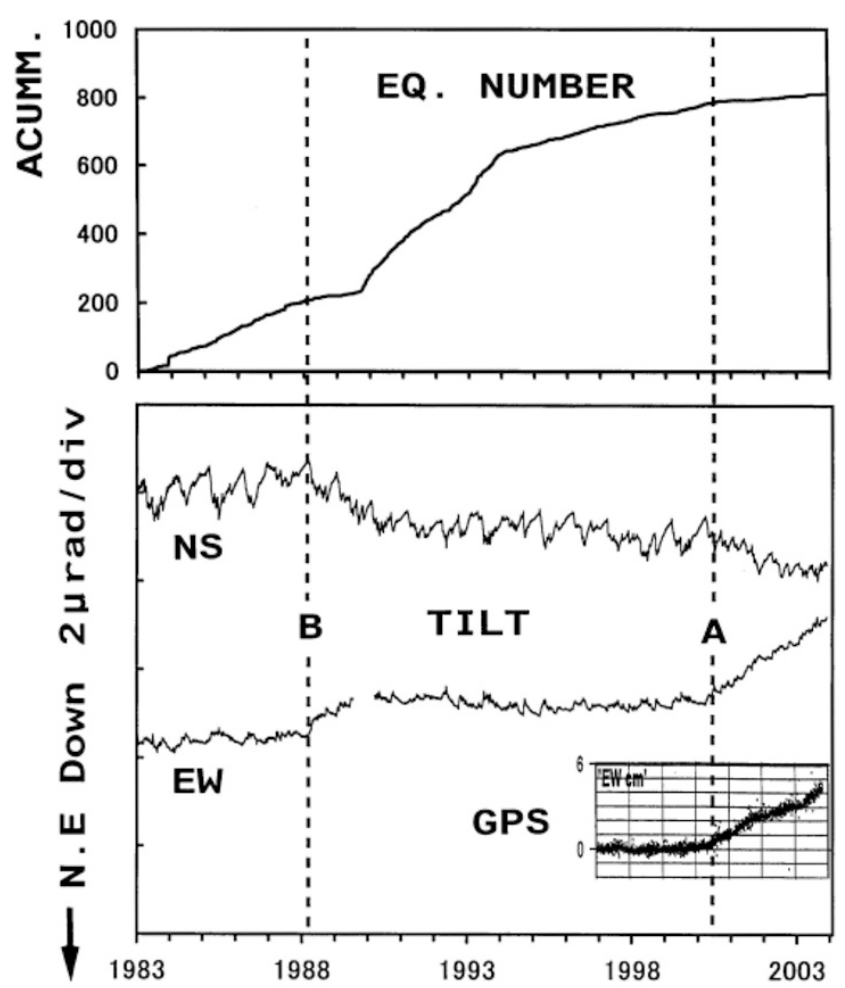

Fig. 3. Bottom figure: Detrended tilt records at MKB obtained by NIED. Inset: East-west displacements of the GPS record at HMK obtained by GSI (GSI, 2003). Top figure: Cumulative frequency of earthquakes of M1.5 and greater and with depths shallower than $50 \mathrm{~km}$ sampled in the region depicted in Fig. 2. Anomalous tilt changes and seismic quiescences are recognized to occur simultaneously along dotted lines $\mathrm{A}$ and $\mathrm{B}$.

the locations of the Mikkabi tilt observation point of NIED (MKB) and the Hamakita GPS observation point of GSI (instead of the point number 93097 assigned by GSI, we refer to this point as HMK in this paper). The rectangular area in Fig. 2 denotes a study area of seismic activity associated with the slow slips (earthquakes greater than M1.5 and shallower than $50 \mathrm{~km}$ are plotted). The observation results at these points are summarized in Fig. 3. The tilt records at MKB from Jan. 1, 1983, to Nov. 30, 2003, are shown together with the east-west displacements measured by GPS at HMK (GSI, 2003). The upper portion of Fig. 3 presents the cumulative number of earthquakes shown in Fig. 2. For the tilt records, long-term trends were removed from the raw data by approximation with an exponential function; step-like changes and anomalous changes due to instrumental troubles were also removed in routine data processing.

According to the tilt and GPS records, anomalous changes began at the time indicated by the broken line A in Fig. 3. These changes correspond to the current slow slip. During the same time period, the slope of the cumulative curve for the number of earthquakes decreases, indicating seismic quiescence. Figure 4 is a contour diagram of the vertical displacement over two years, obtained from GPS observation results (GSI, 2003). In this figure, anomalous tilt changes after the broken line $\mathrm{A}$ at MKB are superimposed as vector $\mathrm{A}$. The tilting change at MKB is east-southeast upward, in the same direction indicated by the upheaval center obtained from GPS observation of ver-

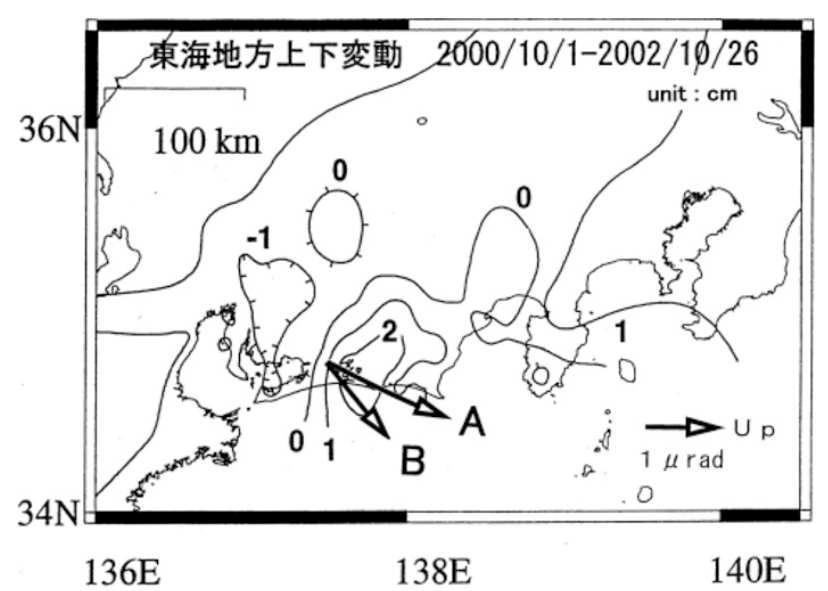

Fig. 4. Upward tilt vectors of the anomalous changes at dotted lines A and B in Fig. 3, superimposed on a contour map of ground upheaval obtained from the GPS observations by GSI (referred to and modified from GSI, 2003).

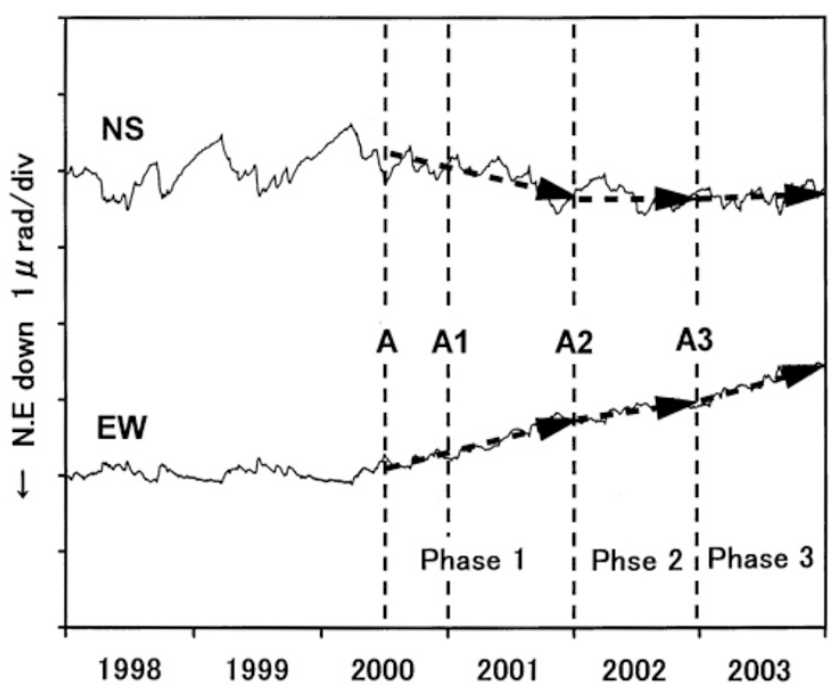

Fig. 5. Tilt records at MKB for Jan. 1, 1998, to Dec. 31, 2003. Anomalous tilt change commenced at dotted line A (same as that in Fig. 3), subsequently changing its trend in the beginning of 2002 (dotted line A2) and again in the beginning of 2003 (dotted line A3).

tical movements. The amount of tilt variation is about 2 microradians, almost equal to the tilt change around MKB estimated from vertical components of the GPS data.

Inspecting the tilt record at MKB in more detail, the tilt record from mid-2000 to the end of 2003 is subdivided into three phases as follows (see Fig. 5). In the first phase, from mid 2000, the tilt direction was east-southeast upward (Phase 1). In the second phase, from the beginning of 2002, the tilt became east upward and the tilting rate decreased to half that of the first phase (Phase 2). This trend lasted until the end of 2002. In the final phase, from the beginning of 2003, the rate increased again while maintaining the same east upward direction (Phase 3). Figures 6(a), (b), and (c) are contour diagrams of the annual vertical movement in 2001, 2002 and 2003, provided by GSI (2004). In Fig. 6, yearly tilting vectors for the corresponding time periods at MKB (A1, A2, and A3) are superimposed. As is shown in this figure, the change in the tilting direction at MKB from 

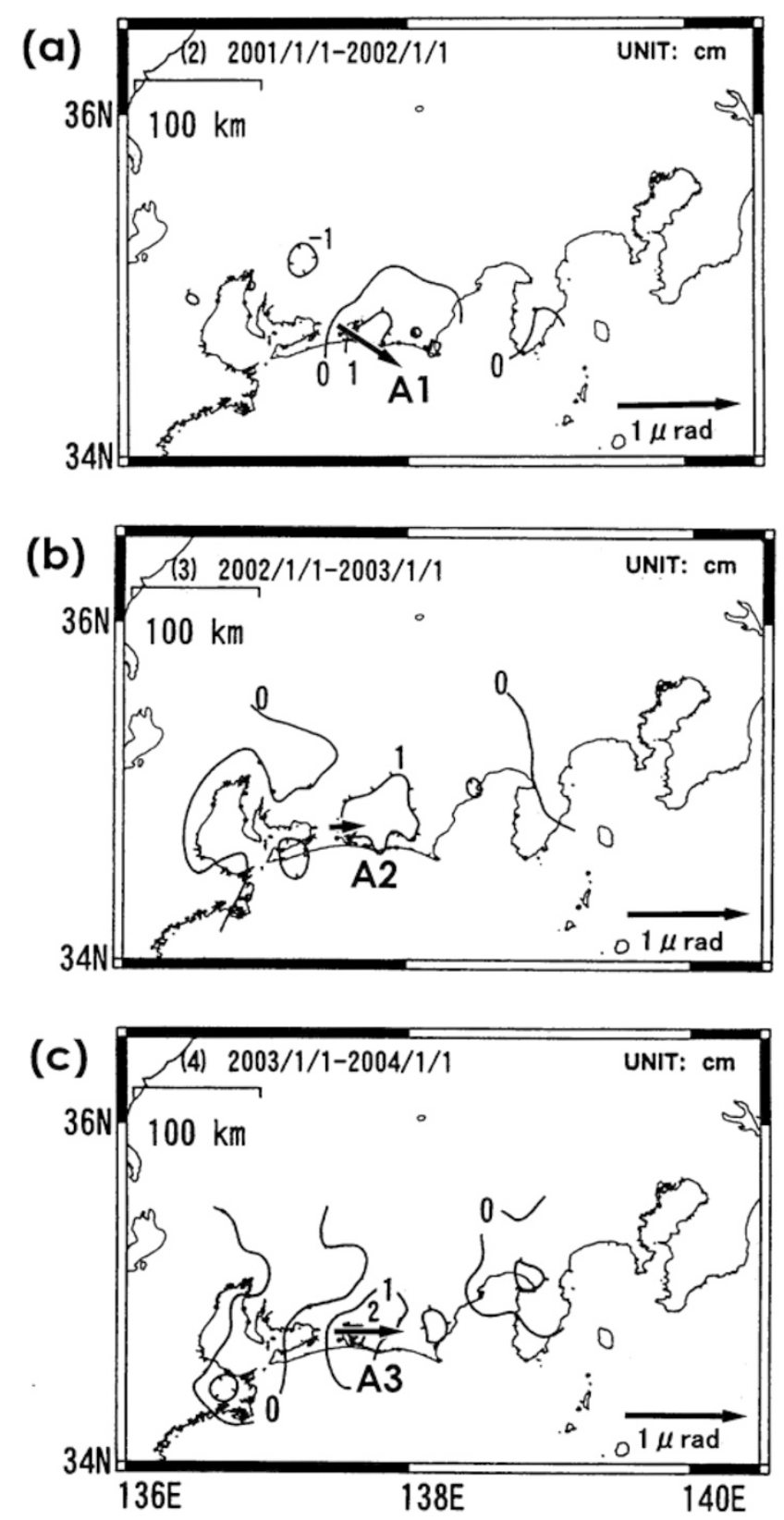

Fig. 6. Comparison between tilt changes and GPS observations. The contour maps are annual ground upheaval maps obtained from the GPS observations by GSI. (a) 2001. (b) 2002. (c) 2003. Arrows superimposed on each figure represent vectors for the yearly tilt changes at MKB (referred to and modified from GSI, 2004).

east-southeast upward (vector A1) to east (vector A2) is consistent with the GPS observation results, which indicate that the center of the upheaval area moved slightly to the east from the south-east of Lake Hamana in 2002. Furthermore, the GPS data shows a larger amount of upheaval in 2003, corresponding to the tilting rate increase. These comparisons demonstrate that tilt observations at MKB reflect the status of a slow slip event beneath Lake Hamana and its temporal changes. This warrants that retrospective investigation of slow slip events using the tilt record at MKB is reliable and worth trying for quantitative discussion.

\section{Slow Slip Event in 1988 to 1990}

Although the tilt observations at MKB began in 1981, the record for the first two years was slightly affected by initial transient changes, so we confined our investigation to the tilt record after 1983.

As the preceding section indicates, the beginning of the current anomalous tilting movement is indicated by broken line A in Fig. 3. Re-investigation of the tilt records reveals a similar anomalous movement lasting two years beginning in April 1988, as indicated by broken line B in Fig. 3. Furthermore, the cumulative number of earthquakes shown in the same figure decreased during that period, indicating a relatively quiescent state. Vector B in Fig. 4 denotes the anomalous tilt change. Though the magnitude of vector $B$ is around half that of vector $\mathrm{A}$, the direction of the movement is approximately the same. These seismicity and tilt anomalies indicate that a slow slip event similar to the current one occurred in the 1988 to 1990 period. These are the only anomalies we could find in the tilt record at MKB before the present ongoing event.

\section{Monitoring of Tilting Movements in the Tokai Area}

The last slow slip event (1988 to 1990) ended without leading to the anticipated Tokai earthquake. The current event, beginning in mid 2000, is still in progress despite the passing of four years. Such a slip occurring close to the assumed focal zone may increase stress in that zone, potentially promoting the Tokai earthquake. Thus, it is important to provide enhanced observation and continued monitoring in this area. NIED has established one or two tilt observation points in the assumed focal zone for the Tokai earthquake every year since 1999; the current tilt observation network is illustrated in Fig. 7. To detect anomalous changes efficiently, the observation points were arranged linearly along the subduction direction of the Philippine Sea plate. Two groups of linearly aligned stations have been formed by adding new stations to the existing ones in the western and central parts of Shizuoka Prefecture (L1 and L2 in the figure). While the tiltmeters at the existing stations were initially installed at the bottom of $100 \mathrm{~m}$-deep observation wells, the depth was increased to $200 \mathrm{~m}$ at some of the new stations.

As depicted in Fig. 7, three new stations belonging to the western group, KG2, MRI, and TAT, are situated close to the slipping region in eastern Lake Hamana. Figure 8 presents the tilt records at these stations along with daily rain data over three months. Although tidal components of the order of $10^{-7}$ appear in the raw data, such changes can be removed through tidal analysis. The results of tidal component removal using BAYTAP-G (Tamura et al., 1991) are shown under each raw data trace. Rain is generally a serious noise source in continuous tilt observations. However, that effect is suppressed to under 0.05 microradians at these three stations because of their installation in deep wells. Besides these changes, noise of unknown origin appeared at some stations. In total, the noise level at these stations is estimated to be less than 0.1 microradians.

Based on a friction constitutive law derived from laboratory rock experiments, Kato and Hirasawa (1999) simulated 


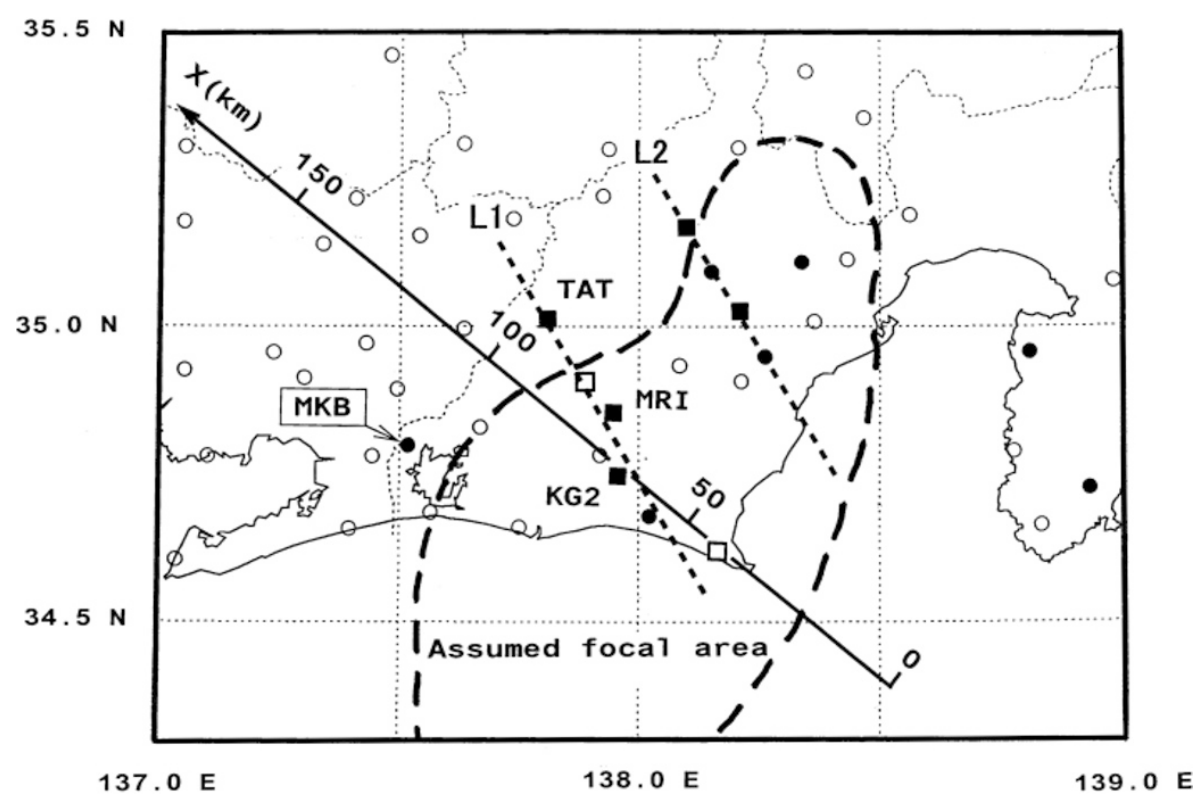

Fig. 7. Location of the current tilt stations of NIED. Solid circles: Stations constructed in the first phase of the special research project for earthquake prediction in the Kanto-Tokai area. Solid squares: Stations recently constructed in the Tokai area. Open circles: Stations of the nationwide network named Hi-net. Open squares: Other stations. Line X is a reference axis used in the simulation model provided by Kato and Hirasawa (1999), as shown in Fig. 9.

the occurrence of an interplate earthquake and the quasistable slip process that is considered to occur at a preliminary stage. Though a detailed description of their method is omitted here, calculations were made on some typical conditions in the Tokai area; the results are depicted as timeseries changes in displacement, stress, and tilt. Figure 9 illustrates the spatial arrangement of the model (cited from Kato and Hirasawa, 1999). The line marked X in Fig. 7 represents a trace of the surface of this model. The relative positions of stations KG2, MRI, and TAT are also plotted in Fig. 9. Figure 10(a) (cited from Kato and Hirasawa, 1999) presents the simulated result for a representative case, which indicates tilt changes approaching final breakage, obtained at distances of $40 \mathrm{~km}, 50 \mathrm{~km}, 60 \mathrm{~km}$, $70 \mathrm{~km}$, and $80 \mathrm{~km}$ away from the origin (O). Tilt changes accompanying the quasi-stable slip begin one or two days prior to the breakage and become obvious several hours before the earthquake. Figure 10(b) depicts the tilt records at KG2, MRI, and TAT, superposed with simulated movement at $80 \mathrm{~km}$ using the same scale. Comparing the observed and simulated results, we see that a quasi-stable slip prior to an earthquake would be detectable at several stations close to the assumed focal zone, if the real situation progresses similarly to the simulated one. Thus the newly installed stations, in cooperation with the pre-existing ones, are expected to become a powerful tool for monitoring the forthcoming Tokai earthquake. Furthermore, initial data variations due to recent installation have been decreasing year by year at the newer stations, so they will be capable of detecting eastward extension of the Tokai slow slip.

\section{Discussion}

The recently established GPS observation network has detected several slow slip events in various plate subduction areas. In the eastern Boso Peninsula, anomalous crustal

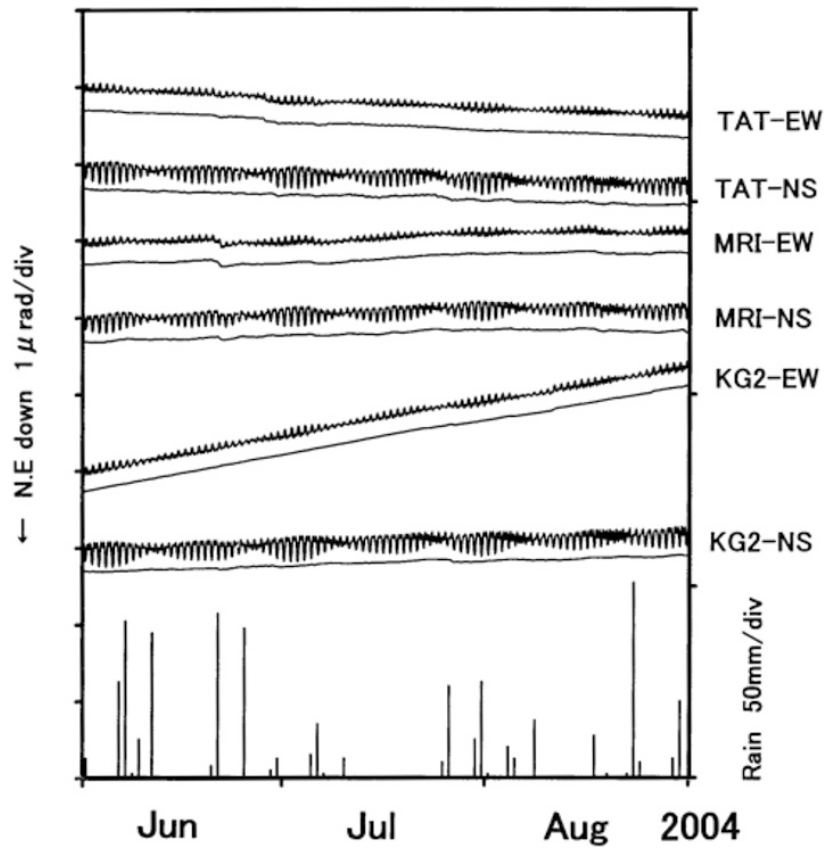

Fig. 8. Raw and tide-removed records of hourly tilt at KG2, MRI, and TAT stations for June 1 to August 31, 2004. The bottom bars are daily rain data observed at a neighboring station.

movements were observed in association with earthquake swarms in May 1996 and October 2002. Analyzing the results of GPS observations, Ozawa et al. (2003) and Sagiya (2004) conjectured that these movements were caused by slow slip events in the uppermost part of the Philippine Sea plate, just beneath the sea off the east to southeast coast of Boso Peninsula (see Fig. 1). These events were also detected in the tilt observations conducted by NIED at the Katsuura Station (KTU) (Yamamoto and Ohkubo, 


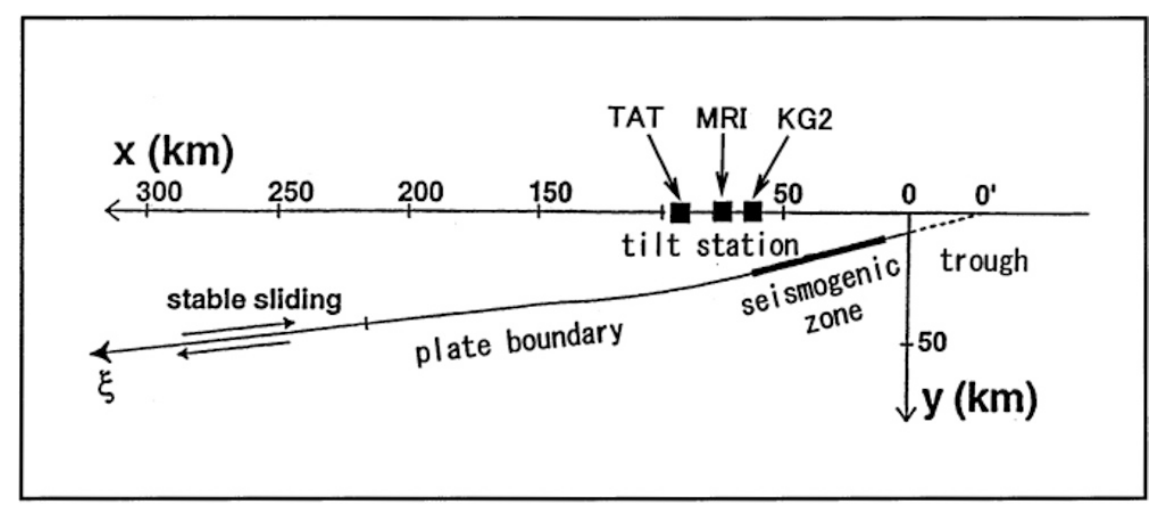

Fig. 9. Setting of the simulation model proposed by Kato and Hirasawa (1999), where the anticipated Tokai earthquake is simulated on the basis of the rate- and state-dependent friction law. Solid squares on the $\mathrm{X}$ axis represent the corresponding positions of the NIED tilt stations, where we investigated the detectability of precursory tilt changes by comparing their signals with the simulated results (referred to and modified from Kato and Hirasawa, 1999).
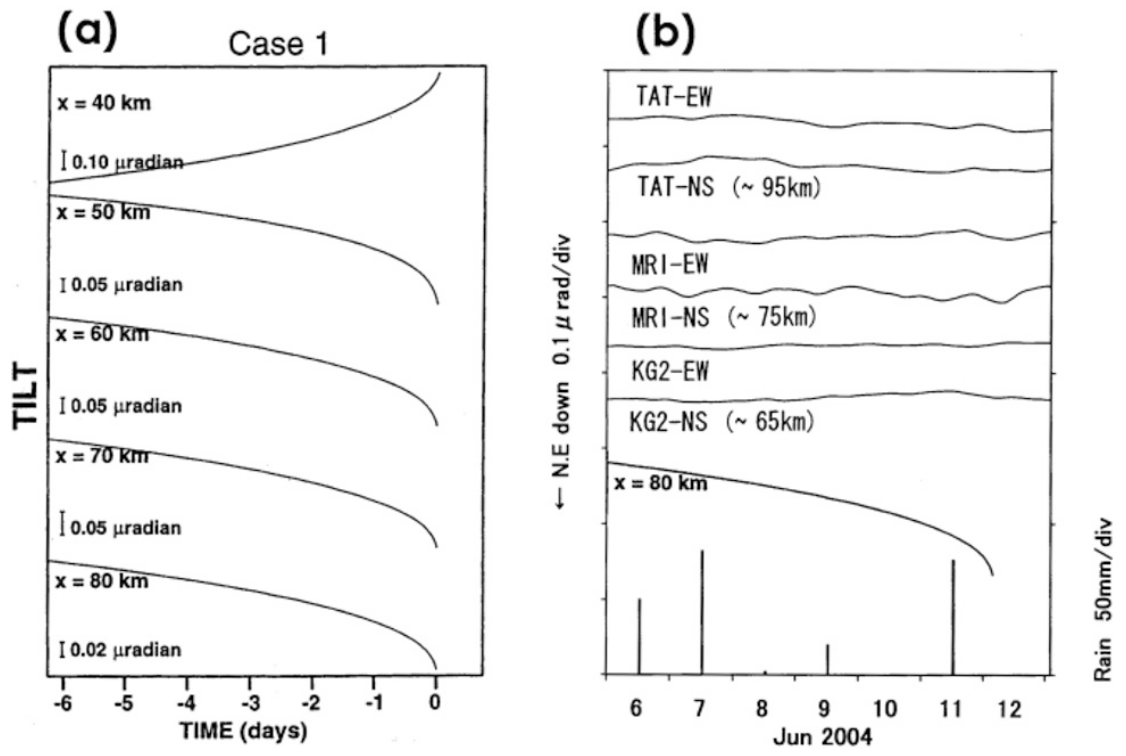

Fig. 10. Comparison between the tilt records obtained from the simulation and those from the observation. (a) Simulated tilt changes for the six days prior to the final breakage. (b) Observed tilt changes at KG2, MRI, and TAT stations, detrended and tide-free. The bottom curve is the same as the simulated tilt at $x=80 \mathrm{~km}$ from (a), depicted in the same scale. Numerals in parentheses indicate the distance from the origin along the $\mathrm{X}$-axis in Figs. 7 and 9.

2003). A review of the data acquired since 1983 at this station revealed that similar tilting movements associated with earthquake swarms occurred in December 1990 and May 1983 (Yamamoto and Ohkubo, 2003). These slow slips are occurring repeatedly in this area with intervals of six to seven years.

It has been reported that an interplate slow slip occurred from 1996 to 1997 in the area extending from western Shikoku to the Bungo strait (Hirose et al., 1999). Similar movements were detected in this area in 2003 (Ozawa et al., 2004). Overseas, crustal movements conjectured to be caused by slow slips have been detected in the Cascadia Subduction Zone (Dragert et al., 2001), occurring at approximately 14-month intervals (Miller et al., 2002).

Thus, slow slips reported in various parts of the world seem to be occurring at approximately constant intervals. Though the interval and the duration vary from one location to another, the slips commonly occur in areas where oceanic plates converge and in the transition area between the locked zone and the stable sliding zone. Also, a slow slip similar to the current one occurred in the Tokai area from 1988 to 1990 . It is highly probable that the slow slips will continue to occur in this area, like other areas where they have been repeatedly observed. However, it should be noted that there is a distinct difference in repetition style between the Tokai slow slips and the others. Specifically, both the magnitude and duration of the current slip are double those of the previous slip (as of the end of 2004). Therefore, the slow slip in the Tokai area may not repeat in exactly the same way.

Although the slow slips were first discovered by a GPS dense array, the present study demonstrated that a tiltmeter is also capable of detecting slow events lasting longer than several years. It has long been believed that tilt and strain meters may not be effective for detecting long-term tectonic deformations due to high environmental noise (e.g. Shichi 
and Okada, 1979). However, the present study suggests that this may not be the case. If the observation conditions are high quality, with the selection of geologically good sites, the usage of highly stable sensors in deep boreholes, and the best possible cementing of the observation wells in contact with surrounding rocks (Sato et al., 1980), then it is possible to detect subtle changes in the crust as small as one microradian, as shown in Fig. 3.

Recently, a dense seismic array called Hi-net operated by NIED found so-called deep, long-period tremors along the subducting Philippine Sea Plate (Obara, 2002). Moreover, Obara et al. (2004) investigated the tilt data from Hi-net and found that the tremor activities are synchronized with slow slips in the same region as the hypocenter of the tremors.

These lines of evidence suggest that the combination of dense arrays of seismometers, GPS, and tiltmeters will be a powerful tool for detecting subtle slow slip events that have never been detected using only GPS. Detection of such small, slow events might lead to detecting a precursory slip toward a subsequent large earthquake.

\section{Concluding Remarks}

Tilt observations over 20 years have revealed a high probability that a slow slip similar to the one in progress in the Tokai area also occurred 15 years ago in approximately the same location. Such a slow slip may occur repeatedly in the Tokai area, as do the slow slips in other areas. However, the current slip is not a mere repetition of the past, as explained in the previous section, and its magnitude had already exceeded Mw 7.0 as of the beginning of 2004 (GSI, 2005). The most serious matter of concern is the possibility that the slow slip will trigger the Tokai earthquake. We have insufficient means and experience to predict such an event definitely. A simulated result assuming various parameters and certain constraints merely shows one of the infinite possibilities.

A major question still remains as to whether tilt or other deformation observations can detect precursors. A discouraging example is the Tokachi-Oki earthquake (M8.0) on September 26, 2003, which did not provide us with any significant precursory deformation just before the earthquake (e.g. Hirose, 2004). However, it should be noted that the observation conditions were rather poor in the case of the Tokachi-Oki earthquake; the nearest observation point was $100 \mathrm{~km}$ from the epicenter. The Tokai area has much better conditions because the observation network is much closer to the hypothetical source region. The enhanced monitoring network for tilt and seismicity in the Tokai area is now capable of detecting subtle changes associated with slow-slip events. We believe that this network will become a powerful tool for detecting an anomalous change prior to the coming Tokai earthquake and will contribute to its successful prediction. However, higher quality, denser observations are still needed in the area in order to realize the prediction.

Acknowledgments. We would like to thank Dr. John Beavan, Dr. Takeshi Sagiya, and an anonymous reviewer for their helpful comments and suggestions that greatly improved this paper.

\section{References}

Central Disaster Management Council, Report of Special Board of Inquiry on Tokai Earthquake, 1-8, 2001 (in Japanese).

Dragert, H., K. Wang, and T. S. James, A silent slip event on the deeper cascadia subduction interface, Science, 292, 1525-1528, 2001.

Geographical Survey Institute, Crustal movements in the Tokai district, Rep. Coord. Commit. Eq. Pred., 69, 303-393, 2003 (in Japanese).

Geographical Survey Institute, Crustal movements in the Tokai district, Rep. Coord. Commit. Eq. Pred., 71, 481-583, 2004 (in Japanese).

Geographical Survey Institute, Crustal movements in the Tokai district, Rep. Coord. Commit. Eq. Pred., 73, 166-237, 2005 (in Japanese).

Hirose, H., Hi-net tiltmeter records prior to the 2003 Tokachi-oki earthquake, Coord. Commit. Eq. Pred., 71, 194-202, 2004 (in Japanese).

Hirose, H., K. Hirahara, F. Kimata, N. Fujii, and S. Miyazaki, A slow thrust slip event following the two 1996 Hyuganada earthquakes beneath the Bungo Channel, southwest Japan, Geophys. Res. Lett., 26, 3237-3240, 1999.

Ishibashi, K., Specification of soon-to-occur seismic faulting in the Tokai district, central Japan, based upon seismotectonics, in Earthquake Prediction: An International Review, edited by D. W. Simpson and P. G. Richards, pp. 297-332, American Geophysical Union, Washington, D.C., 1981.

Ishida, M., Geometry and relative motion of the Philippine Sea Plate and Pacific Plate beneath the Kanto-Tokai district, Japan, J. Geophys. Res., 97, 489-513, 1992.

Kato, N. and T. Hirasawa, A model for possible crustal deformation prior to a coming large interplate earthquake in the Tokai district, Central Japan, Bull. Seism. Soc. Am., 89, 1401-1417, 1999.

Matsumura, S., Focal zone of a future Tokai earthquake inferred from the seismicity pattern around the plate interface, Tectnophysics, 273, 271291, 1997.

Matsumura, S., Seismic quiescence in the inferred locked zone in Tokai district and its interpretation, Gekkan Chikyu, 33, 33-43, 2001 (in Japanese).

Matsumura, S., Seismicity rate change in the inferred locked zone of the tokai region in the latter half of the 1990's, Zisin, 54, 449-463, 2002 (in Japanese).

Miller, M. M., T. Melbourne, D. J. Johnson, and W. Q. Sumner, Periodic slow Earthquakes from the Cascadia Subduction Zone, Science, 295, 2423, 2002.

Obara, K., Nonvolcanic deep tremor associated with subduction in southwest Japan, Science, 296, 1679-1681, 2002.

Obara, K., H. Hirose, F. Yamamizu, and K. Kasahara, Episodic slow slip events accompanied by non-volcanic tremors in southwest Japan subduction zone, Geophys. Res. Lett., 31, L23602, doi:10.1029/2004GL020848, 2004.

Ozawa, S., M. Makoto, M. Kaidzu, T. Tada, T. Sagiya, Y. Hatanaka, H. Yanai, and T. Nishimura, Detection and monitoring of ongoing aseismic slip in the Tokai region, central Japan, Science, 298, 1009-1012, 2002.

Ozawa, S., S. Miyazaki, Y. Hatanaka, T. Imakiire, M. Kaidzu, and M. Murakami, Characteristic silent earthquakes in the eastern part of the Boso Peninsula, Centaral Japan, Geophys. Res. Lett., 30(16), 1-4, 2003.

Ozawa, S., Y. Hatanaka, M. Kaidzu, M. Murakami, T. Imakiire, and Y. Ishigaki, Aseismic slip and low-frequency earthquakes in the Bungo channel, southwestern Japan, Geophys. Res. Lett., 31, L07609, 2004.

Sagiya, T., Interplate coupling in the Kanto district, central Japan, and the Boso silent earthquake in May 1996, PAGEOPH, 161(11-12), 26012616, 2004.

Sato, H., H. Takahashi, E. Yamamoto, N. Fukuo, M. Uehara, and Y. Terasawa, Development of the crustal tilt observation method using borehole-type tiltmeters, Zisin, 33, 343-368, 1980 (in Japanese).

Shichi, R. and Y. Okada, Strain measurement in the vault, J. Geod. Soc. Japan, 25, 101-134, 1979 (in Japanese).

Tamura, Y., T. Sato, M. Ooe, and M. Ishiguro, A procedure for tidal analysis with a Bayesian information criterion, Geophys. J. Int., 104, 507-516, 1991.

Yamamoto, E. and T. Ohkubo, Slow slip event detected by continuous tilt observation, occurred around eastern Boso Peninsula in Oct. 2002, Coord. Commit. Eq. Pred., 69, 198-204, 2003 (in Japanese).

E. Yamamoto (e-mail: yamamoto@bosai.go.jp), S. Matsumura, and T. Ohkubo 